\title{
Contribuições do Design Editorial para a Alfabetização Infantil
}

\author{
Editorial Design's contributions for Children's Literacy
}

Sara Copetti Klohn, Thais Arnold Fensterseifer

design editorial, design de livros, livros infantis

\begin{abstract}
Este artigo apresenta a metodologia e os resultados de uma pesquisa de campo desenvolvida junto a crianças de seis a sete anos em uma escola pública municipal, visando à identificação dos fatores em design editorial (tais como tipografia, diagramação, formato e adequação ergonômica, técnicas e estilos de ilustração) mais adequados para estimular o interesse desse público pelos livros e para instigar a aquisição do hábito da leitura desde os primeiros anos de vida. Para tanto, reúnem-se informações quanto às preferências e aos hábitos infantis no que tange a leitura, relevantes para o futuro desenvolvimento de uma série de livros infantis.
\end{abstract}

editorial design, book design, children's books

This paper presents the methodology and the results of a survey developed with children aged six to seven years in a public school, in order to identify which items in Editorial Design (such as typography, layout, format and ergonomy, techniques and styles of illustration) are most appropriate to stimulate children's interest in books and to encourage the acquisition of reading skills from the earliest years of life. Aiming this objective, the present survey gathers information regarding the preferences and the habits when it comes to children's reading - relevant data for the future development of a series of children's books.

\section{Introdução}

Dada a relevância do projeto editorial para a área do design gráfico e a importância da aquisição do hábito da leitura desde a infância, considera-se bastante pertinente fazer um elo entre esses temas. De acordo com Munari (2008), é durante a infância que se desenvolvem os hábitos que serão levados com o indivíduo durante toda a vida, motivo pelo qual se torna tão relevante incentivar o gosto pelos livros desde a infância.

A principal justificativa para essa pesquisa caracteriza-se na percepção da importância do assunto, norteada pela afirmação de Chartier (apud FARBIARZ et al, 2010), que enfatiza que a forma do livro pode interferir tanto no sentido dado ao texto quanto no uso que esse livro possa ter para o usuário. Conforme o autor, o designer atua como mais um agente no processo de formação do leitor e pode, por meio do desenvolvimento de um projeto editorial coerente e alinhado com as necessidades do público-alvo, incentivar a leitura e o interesse pelos livros: cumpre, assim, seu papel social.

Para embasar o desenvolvimento de uma coleção de livros infantis (aspecto que não será abordado neste artigo) que atinja os objetivos de facilitar o acesso à leitura e de incentivar o gosto pelos livros, fez-se necessário realizar uma revisão bibliográfica, abrangendo os diversos aspectos que permeiam o universo do desenvolvimento do projeto gráfico de um livro. Ao término dessa revisão, fez-se a pesquisa de campo (foco deste artigo), que permitiu um contato mais próximo com as crianças a fim de verificar requisitos e restrições complementares à pesquisa bibliográfica.

\section{Revisão bibliográfica}

De acordo com Syndi Kauffman (2005), as crianças usam uma grande variedade de 
ferramentas para realizar a seleção de um livro para leitura. $O$ autor afirma que muitos estudos foram realizados a fim de determinar quais as características desejáveis em um livro para que ele seja selecionado por uma criança - incluindo, até mesmo, o impacto dos elementos da história neste processo. A editora HIP Books (2011) acrescenta que mesmo bons e habituais leitores adultos podem frustrar-se ao se depararem com livros compostos em tipos muito pequenos ou com espaçamento entre linhas - chamado leading - muito 'apertado'. Se, mesmo para os leitores mais experientes, o design da página pode fazer a diferença na experiência de leitura, esse fator é especialmente importante e crucial para leitores iniciantes ou inexperientes, como as crianças (H-I-P Books, 2011). Embora não haja uma regra fixa, é consenso que a escolha de tipos, a diagramação, os espaçamentos e a extensão das margens são fundamentais para que se tenha um texto mais acessível (CORDEIRO apud LOURENÇO, 2011).

A temática do livro é outro fator que exerce influência sobre as crianças, que apreciam temas que se aproximem de seu cotidiano (SHAFER apud KAUFFMAN, 2005). Os contos de fada, que sintetizam pela ficção uma realidade vivenciada pelo leitor, igualmente atraem sua atenção (ZILBERMAN apud FERRARI, 2008). De acordo com Faust (apud RAMOS et al, 2008), o uso da cor também ocupa papel central, pois o colorido dos livros dá à criança 'o prazer do jogo visual', despertando sua curiosidade. Coelho (apud RAMOS et al, 2008) acrescenta que a paleta de cores para o público infantil deve conter tons vivos e contrastantes.

A ilustração, por sua vez, é considerada fator crucial nos livros infantis: as figuras ajudam a desenvolver o interesse pela leitura, facilitando a identificação de novas palavras e estimulando verbalizações (MELLO apud RAMOS, 2008). De acordo com Lins (2003), o livro infantil tem o papel de estimular a criança, e é a imagem que complementa e enriquece a história escrita ela caracteriza os personagens da trama, atribuindo a eles personalidade, idade e figurino, e situando-os em diferentes épocas e locais geográficos. Zimmermann (2008, p. 81) acrescenta que as ilustrações participam da formação da história, deixando lacunas a serem preenchidas pelo leitor: cabe a ele "imaginar o que teria ocorrido de uma página a outra, fazendo com que este também interaja na construção da obra".

Os materiais, acabamentos e outros recursos gráficos também podem contribuir para atrair esse público: facas de corte especiais, papéis com textura diferenciada, dobras e vincos podem contribuir para tornar o livro ainda mais atrativo, aumentando a interatividade entre o leitor e a obra e convidando-o a explorar outros sentidos, além da visão.

\section{Metodologia}

A pesquisa de campo com amostragem do público-alvo foi realizada para reunir elementos complementares à coleta de dados realizada na pesquisa bibliográfica. A pesquisa foi realizada na Escola Estadual de Ensino Fundamental General Bento Gonçalves da Silva, localizada na cidade de Bento Gonçalves - RS, com os alunos da primeira série do Ensino Fundamental, que tem aulas ministradas pela Prof ${ }^{a}$. Márcia Donini. O grupo constitui-se de vinte e dois alunos (dez meninos e doze meninas), com idades entre seis e sete anos. As crianças da turma já possuem o hábito da leitura de livros infantis na escola, em que vão à biblioteca, participam da "hora do conto" e leem em sala de aula.

A coleta de dados foi instrumentalizada por meio de duas entrevistas: entrevista geral com a turma e entrevista individual com cada aluno. Seguiram-se roteiros pré-formatados e, além das anotações, foi realizada a gravação das entrevistas. Foram utilizados sete livros infantis como apoio e foram feitas fotografias do uso dos livros pelas crianças ${ }^{1}$.

$\mathrm{Na}$ data agendada, iniciou-se a pesquisa com uma apresentação, aos alunos no grande grupo, da pesquisadora e dos objetivos deste estudo, procurando-se utilizar uma linguagem simples e adequada ao público. Em seguida, utilizando-se os livros infantis como apoio, foi aplicado o roteiro da entrevista geral, que a turma respondeu em grupo, levantando as mãos

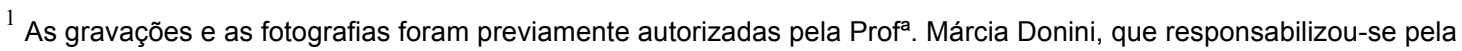
obtenção das autorizações junto aos pais dos alunos e à diretoria da escola.
} 
para sinalizar suas preferências com relação aos livros e falando, em voz alta, seus comentários sobre determinados aspectos. Ao final dessa primeira entrevista, os livros foram distribuídos entre as crianças, que puderam folheá-los, lê-los e analisá-los de acordo com a sua perspectiva individual. Foi realizado o registro fotográfico dessa etapa. A seguir, enquanto o grande grupo seguia fazendo uso dos livros, as crianças foram sendo chamadas, uma a uma, para responder à entrevista individual. Na etapa de análise de dados, as informações foram agrupadas quantitativamente. Essa análise também procurou contemplar comentários selecionados dentre a totalidade das entrevistas e que poderão ser úteis como diretrizes para o futuro desenvolvimento da série de livros.

\section{Resultados}

A primeira parte da entrevista geral permitiu perceber a preferência do público por capas de livro coloridas e vibrantes. Foram desenvolvidas sete variações cromáticas da capa original do livro "365 Pinguins", de Jean-Luc Fromental, para apresentação às crianças. Antes de serem convidadas a escolherem a sua capa favorita, as crianças puderem observar cada uma das opções de capas disponíveis. Dentre as variações (azul, rosa, roxa, verde e duas capas multicoloridas, além da original, amarela), uma das capas multicoloridas foi a mais votada, recebendo dez dos vinte e dois votos, comprovando as assertivas quanto à paleta de cores descritas na revisão bibliográfica (Figura 01). Muitas crianças, ainda, gostaram da capa rosa meninos, inclusive, que a chamaram "capa vermelha".

Figura 01: À esquerda, capa original do livro "365 Pinguins", de Jean-Luc Fromental.

À direita, variação da capa mais votada pelas crianças.

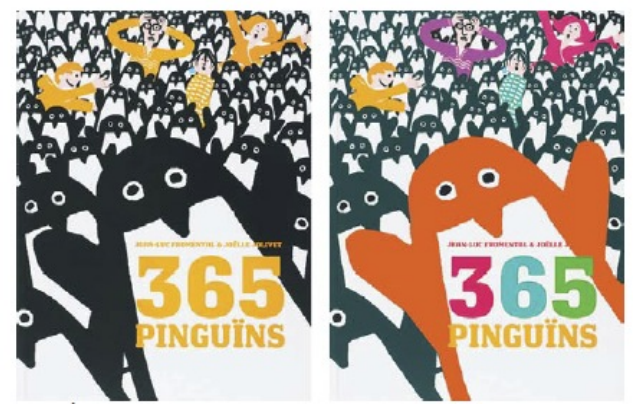

Na próxima pergunta, cujo objetivo era identificar qual o estilo de ilustração preferido pelo público-alvo, foram utilizados os livros infantis como apoio. Mostrou-se uma página interna de cada livro e, após a apresentação de todas, as crianças votaram, levantando as mãos, nas que mais gostaram. Observou-se a dificuldade das crianças em entender que deveriam escolher pelo tipo de ilustração: muitas votaram exclusivamente com base na temática da história. Quase um terço votou na ilustração do livro "Dois Ursos Famintos", de Linda Cornwell, referindo que gostavam muito de histórias com ursos. Foi notável, também, o gosto das crianças pelo livro "365 pinguins", cuja temática também pareceu interessar a eles. Outras crianças acharam divertidas as ilustrações do livro "O Alvo", de Ilan Brenman, comentando que o personagem principal era muito engraçado. A Figura 02 mostra as três ilustrações mais votadas pelas crianças. 
Figura 02: llustrações mais votadas - "365 Pinguins" (Jean-Luc Fromental), "Dois Ursos" (Linda Cornwell) e "O Alvo" (Ilan Brenman).
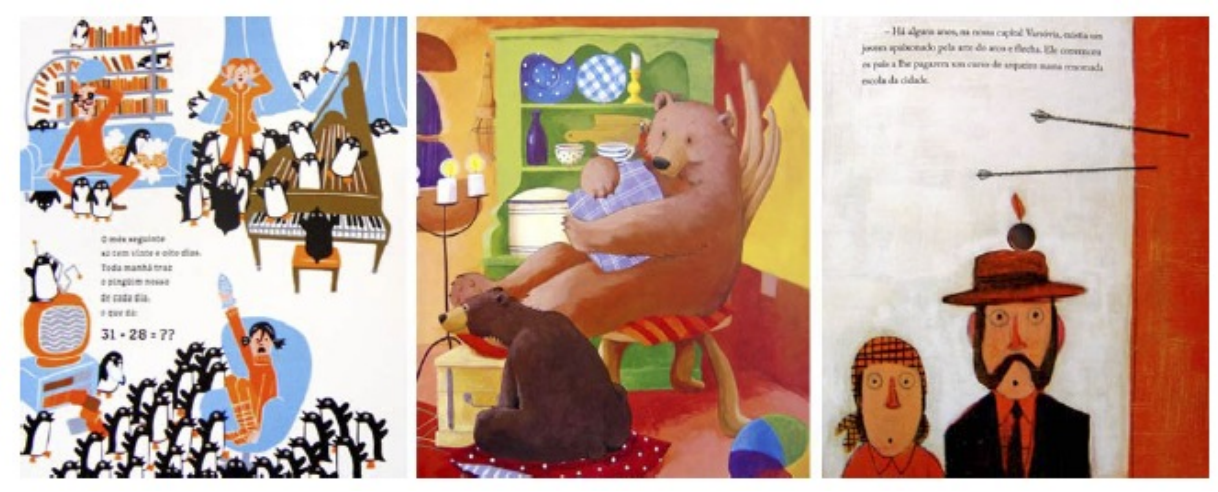

Em seguida, os livros foram distribuídos dentre os alunos, com a finalidade de realizar a observação do uso das obras pelo público-alvo. Percebeu-se que o tamanho maior de alguns livros não foi empecilho para o seu uso, já que as crianças os apoiaram, abertos, sobre o chão ou sobre a mesa. Os formatos retangulares pareceram ser mais facilmente manuseados pelas crianças, enquanto os formatos horizontais geraram maior dificuldade em manter o livro aberto. A Figura 03 mostra essas situações de uso.

Figura 03: Manuseio dos livros pelas crianças.

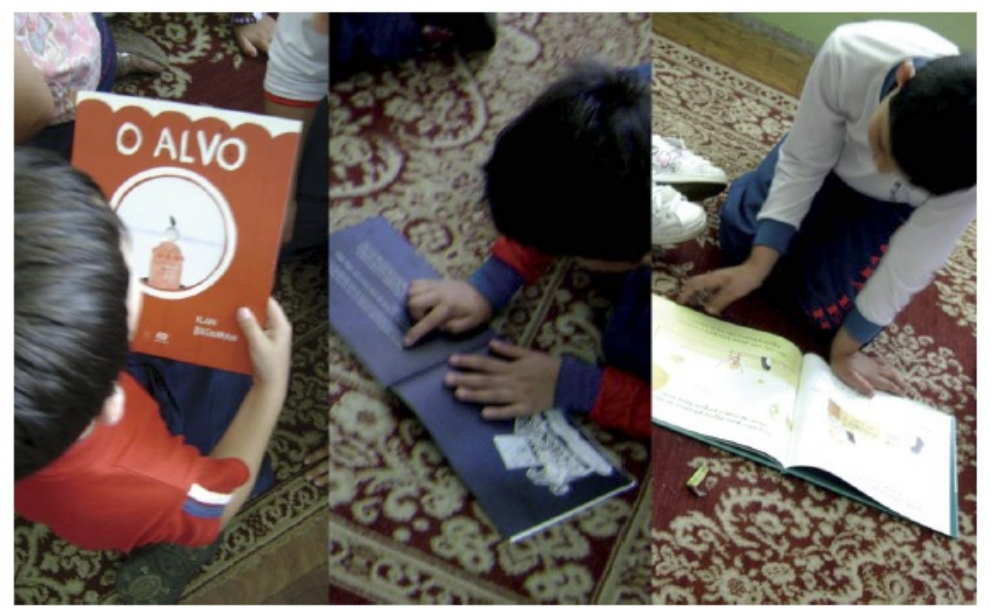

Após manusearem os livros, as crianças foram convidadas a escolherem o seu favorito, levantando a mão para votar no livro selecionado. A Tabela 1 apresenta os resultados, que confirmaram que o livro "365 pinguins" realmente agradou ao público, que também gostou bastante da obra "Dois Ursos Famintos", ratificando o que foi levantado na questão sobre os estilos de ilustração. Foi interessante observar, ainda, que o livro "Branca de Neve e as Sete Versões" foi considerado feminino pelos meninos da turma e que o livro "Biblioburro" não atraiu a atenção dos pequenos, talvez pela temática, afastada de seu cotidiano, talvez pelo estilo de ilustração, mais caricatural - o que pode se justificar, talvez, até mesmo como uma questão cultural. 
Tabela 1: Os livros preferidos pelo público-alvo.

\begin{tabular}{l|c} 
Título do livro & Votos* \\
\hline $\begin{array}{l}\text { Achados e Perdidos } \\
\text { JEFFERS, Oliver. São Paulo: Moderna, 2010. }\end{array}$ & 05 \\
Branca de Neve e as Sete Versões & \\
TORERO, José Roberto. Rio de Janeiro: & 03 \\
Objetiva, 2011. & \\
Dois Ursos Famintos \\
CORNWELL, Linda. São Paulo: Ciranda \\
Cultural, 2010. \\
Biblioburro \\
WINTER, Jeanette. São Paulo: Editora Martins \\
$\begin{array}{l}\text { Fontes, 2011. } \\
\text { O Alvo }\end{array}$ \\
BRENMAN, llan. São Paulo: Ática, 2011. \\
$\begin{array}{l}\text { 365 pinguins } \\
\text { FROMENTAL, Jean-Luc. São Paulo: Cia das }\end{array}$ \\
$\begin{array}{l}\text { Letrinhas, 2008. } \\
\text { O Buraco do Céu }\end{array}$ \\
DERDYK, Edith. O Buraco do Céu. São Paulo: \\
Girafinha, 2009. \\
*foi permitido que cada criança votasse em mais de um livro. \\
\end{tabular}

Finalizando a entrevista geral, questionou-se às crianças o porquê da preferência pelo livro "365 pinguins". Os principais aspectos citados foram a temática do livro, o fato de a história ser engraçada, os personagens e as cores.

Enquanto a maioria da turma continuava a ler, iniciou-se a entrevista individual. Ao todo, dez meninos e dez meninas responderam, um a um, a essa entrevista (quase a totalidade da turma). Dentre os entrevistados, nove alunos possuíam seis anos de idade, enquanto os outros onze contavam sete anos. Entre outros aspectos, as crianças foram questionadas sobre os hábitos de leitura de seus pais, sobre a quantidade de livros que têm em casa, sobre o hábito de os pais lerem junto com as crianças e sobre o desejo de ter mais livros de histórias em casa.

A maioria declarou ter o costume de ler tanto em casa quanto na escola, e foi possível notar que o comportamento dos pais quanto à leitura reflete no dos filhos. Perguntou-se, também, qual o livro e o personagem favorito de cada criança. Os resultados foram bastante variados, e notou-se o gosto das crianças, especialmente das meninas, por histórias com princesas. Personagens clássicos, como Peter Pan e Cinderela, também foram citados, junto a nomes mais atuais, muitos advindos de programas de televisão.

Por fim, as crianças foram convidadas a escolher, dentre quatro títulos de histórias infantis, qual mais gostariam de ler. Os títulos foram selecionados dentre o catálogo de livros infantis de uma livraria porto-alegrense, priorizando-se a escolha de títulos que retratassem diferentes temáticas. A figura 04 apresenta os resultados obtidos. Foi interessante observar que a história "O palácio da princesa sereia" atraiu a atenção da maior fatia do público-alvo, incluindo meninos e meninas, o que comprova o gosto do público pelos contos-de-fadas. O fato de a segunda colocada ser a história "O cãozinho" corrobora com a assertiva de que as crianças gostam de temáticas envolvendo animais. O título "As aventuras do avião vermelho" também teve boa receptividade. 
Figura 04: Respostas dos entrevistados quanto à história que mais lhes atrai o interesse, dentre as quatro citadas.

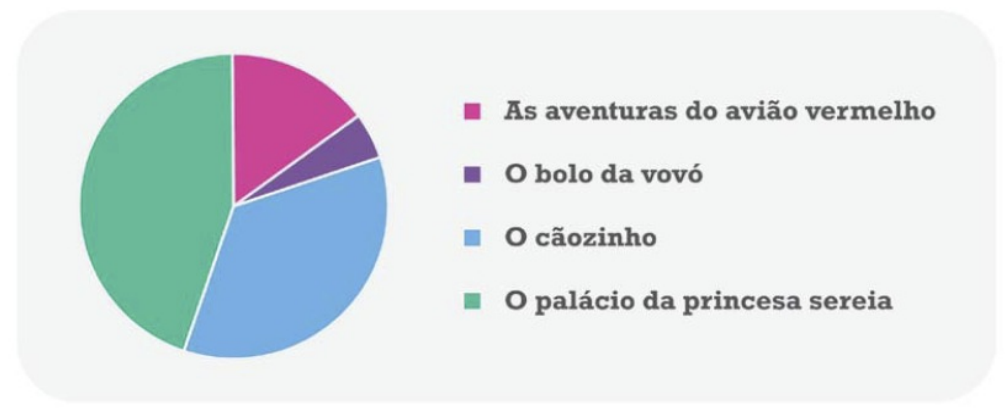

\section{Conclusão}

Ao final da pesquisa com amostragem do público-alvo, pode-se concluir que ouvir a opinião das crianças e observá-las enquanto manuseavam os livros foi uma experiência bastante enriquecedora, que adicionou dados importantes à pesquisa bibliográfica. Esse tipo de pesquisa de campo permite um contato mais próximo com o público-alvo, possibilitando uma melhor compreensão de seus gostos e de seus interesses e permitindo, assim, ter uma fundamentação mais sólida para o desenvolvimento do projeto.

Percebe-se, com isso, a importância da etapa de pesquisa para o desenvolvimento de projetos em design: é esse embasamento que garante maior solidez e consistência ao projeto, munindo o designer de ferramentas que serão imprescindíveis para que se atinjam os objetivos inicialmente definidos.

\section{Referências}

FARBIARZ, Alexandre; FARBIARZ, Jackleline L. O entrelugar do design na interação entre o livro e o leitor. In: Design: olhares sobre o livro. Organização: Luiz A. Coelho et al: Editora Novas Ideias, 2010. P. 139-157.

FERRARI, Amanda Regina. Os contos de fada e as preferências infantis. 2008, Artigo ( $8^{\circ}$ Congresso Nacional de Iniciação Científica - CONIC - SEMESP), Faculdade Anhanguera de Valinhos, Anhanguera Educacional, São Paulo, 2009.

HIP Books. New York, 2011. Disponível em: <http://www.hip-books.com/why_hip_books _work.php? $p=184>$. Acesso em: 17 out. 2011.

KAUFFMAN, Syndi. Story Elements: Which Impact Children's Reading Interests? 2005, Tese (Mestrado em Educação), Centro de Graduação da Universidade Estadual de Bowling Green, Ohio, 2005.

LINS, Guto. Livro Infantil? : projeto gráfico, metodologia, subjetividade. São Paulo: Edições Rosari, 2003.

LOURENÇO, Daniel Alvares. Tipografia para livro de literatura infantil: desenvolvimento de um guia com recomendações tipográficas para designers. 2011, Dissertação (Mestrado em Design), Programa de Pós-graduação em Design, UFPR, Curitiba, 2011.

MUNARI, Bruno. Das coisas nascem coisas. $2^{\mathrm{a}}$ edição. São Paulo: Martins Fontes, 2008.

RAMOS, Oswaldo Alcanfor; WITTER, Geraldina Porto. Influência das cores na motivação para leitura das obras de literatura infantil. In: Scielo, 2008. Disponível em <http://www.scielo.br/pdf/pee/v12n1/v12n1a04.pdf> Acesso em: 17 out. 2011

ZIMMERMANN, Anelise. As ilustrações de livros infantis: o ilustrador, a criança e a cultura. 2008, Dissertação (Mestrado em Artes Visuais), Centro de Artes, Universidade do Estado de Santa Catarina, Florianópolis, 2008. 


\section{Sobre as autoras}

Sara Copetti Klohn, mestre em Design pela Universidade Federal do Rio Grande do Sul, é professora desta mesma Universidade e tem interesse nas seguintes áreas de pesquisa: design gráfico, pictogramas, percepção visual e sustentabilidade.

<sara.copetti@ufrgs.br>

Thais Arnold Fensterseifer, graduanda em Design Visual pela Universidade Federal do Rio Grande do Sul, tem experiência na área de Comunicação Visual, atuando principalmente nas seguintes áreas: design editorial, design gráfico e design de interfaces.

<thaisarnold@gmail.com>

[Artigo recebido em dezembro de 2012, aprovado em dezembro de 2012] 